\title{
Sleep and Obesity in Children and Adolescents
}

\author{
Chantelle N. Hart, Ph.D. ${ }^{a}$, \\ Assistant Professor (Research), Department of Psychiatry \& Human Behavior, The Warren Alpert \\ Medical School of Brown University; and Staff Psychologist, Weight Control \& Diabetes Research \\ Center, The Miriam Hospital
}

Alyssa Cairns ${ }^{b}$, and

Postdoctoral Research Fellow, Department of Psychiatry \& Human Behavior, The Warren Alpert Medical School of Brown University, and Weight Control \& Diabetes Research Center, The Miriam Hospital

Elissa Jelalian, Ph.D. ${ }^{\mathrm{C}}$

Associate Professor, Department of Psychiatry \& Human Behavior, The Warren Alpert Medical School of Brown University; and Staff Psychologist, Weight Control \& Diabetes Research Center, The Miriam Hospital

\section{Synopsis}

The purpose of the present review is to provide a comprehensive update of current epidemiological studies that have assessed the association between sleep and obesity risk. Data from 29 studies conducted in 16 countries suggest that short sleep is associated with an increased risk for being or becoming overweight/obese or having increased body fat. Late bedtimes were also found to be a risk factor for overweight/obesity. Findings also suggest that changes in eating pathways may lead to increased body fat. Future experimental studies are needed to enhance our understanding of the underlying mechanisms through which sleep may play a role in the development and maintenance of childhood obesity.

\section{Keywords}

sleep; obesity; adiposity; eating behaviors; activity behaviors

\section{Introduction}

Pediatric obesity is considered an epidemic with $32 \%$ of U.S. children and adolescents 2-19 years old considered overweight or obese in 2007-2008. ${ }^{1}$ The medical and psychosocial risks associated with being overweight and obese as a child or adolescent have been well

\footnotetext{
(C) 2011 Elsevier Inc. All rights reserved.

a Corresponding author for proof and reprints: Chantelle Hart, Ph.D., Weight Control \& Diabetes Research Center, The Miriam Hospital, 196 Richmond Street, Providence, RI 02903; Chantelle_Hart@brown.edu; 401-793-9727; 401-793-8944 (fax).

${ }^{b}$ Co-author Addresse: Alyssa Cairns, Ph.D., Weight Control \& Diabetes Research Center, The Miriam Hospital, 196 Richmond Street, Providence, RI 02903; acairns@lifespan.org; 401-793-8997; 401-793-8944 (fax).

${ }^{\mathrm{C}}$ Co-author Addresse: Elissa Jelalian, Ph.D., Weight Control \& Diabetes Research Center, The Miriam Hospital, 196 Richmond Street, Providence, RI 02903; Elissa_Jelalian@brown.edu; 401-793-8971; 401-793-8944 (fax).

The authors have nothing to disclose.

Publisher's Disclaimer: This is a PDF file of an unedited manuscript that has been accepted for publication. As a service to our customers we are providing this early version of the manuscript. The manuscript will undergo copyediting, typesetting, and review of the resulting proof before it is published in its final citable form. Please note that during the production process errors may be discovered which could affect the content, and all legal disclaimers that apply to the journal pertain.
} 
documented. Multiple studies have demonstrated the increased risk for Type 2 diabetes and a number of cardiovascular disease risks, including elevations in cholesterol, diastolic and systolic blood pressure, fasting insulin levels, and triglycerides. ${ }^{2-4}$ Children and adolescents who are overweight and obese report lower health related quality of life compared to their normal weight peers, and may be at increased risk of poorer self-esteem, greater body dissatisfaction, and increased peer teasing. ${ }^{5,6}$ The importance of addressing this epidemic is underscored by a number of national policy efforts and by the proposed goals for Healthy People 2020. ${ }^{7}$

Given the precipitous rise in pediatric obesity and its associated risks, increasing attention has been paid to efforts to enhance prevention and treatment approaches. Current prevention approaches have demonstrated variable impact on weight outcomes ${ }^{8}$ with some efficacy shown for school-based approaches that combine diet and physical activity. ${ }^{9}$ A number of intervention approaches for children and adolescents who are overweight and obese have demonstrated efficacy, including those that combine dietary and physical activity prescriptions with the use of effective behavioral strategies. ${ }^{10}$ Use of weight loss medication also has demonstrated efficacy ${ }^{10}$, and surgical approaches also show some promise ${ }^{11}$ within adolescent populations. However, each of these approaches has limitations, and despite their effectiveness, seldom help children and adolescents achieve non-obese status. Thus it is imperative to identify novel targets to enhance current treatment approaches.

A number of factors suggest that enhancing children's sleep may be an effective strategy for preventing and treating pediatric obesity. Over the past 20-30 years, as rates of pediatric obesity have climbed, children's nocturnal sleep duration has declined. ${ }^{12,13}$ Data from the 2004 National Sleep Foundation's (NSF) Sleep in America Poll show that the mean sleep length for school-age children ( $1^{\text {st }}$ to $5^{\text {th }}$ grade) is 9.4 hours/night. ${ }^{14}$ These data are in contrast to recommendations by sleep experts that children in this age group should obtain 10-11 hours/night. ${ }^{15,16}$ Thus, children may not be achieving sufficient sleep length.

In addition to above, experimental studies with adults have documented physiological and behavioral changes in response to sleep deprivation, which, if chronic, may promote weight gain. The secretion of a number of hormones, including growth hormone, prolactin, cortisol, thyrotropin, and insulin, are influenced by sleep. ${ }^{17}$ For example, studies suggest that sleep restriction leads to decreased circulating leptin ${ }^{18,19}$ and increased ghrelin ${ }^{20}$ both of which are associated with increased hunger, appetite, motivation to eat, and food intake. ${ }^{21-23}$ Further, more recent experimental studies with adults have demonstrated increases in caloric intake from both snack foods ${ }^{24}$ and from main meals ${ }^{25}$ when sleep is restricted, suggesting that less sleep may increase the risk of obesity via neuroendocrine changes that increase food intake. Finally, although less is known in this regard, it is hypothesized that sleep deprivation may also lead to changes in physical and sedentary activities, which could promote weight gain. Limited support for this hypothesis comes from studies with adults that have demonstrated subsequent decreases in activity level following sleep deprivation. ${ }^{26,27}$

To our knowledge, no experimental studies involving the manipulation of sleep in children and weight-related outcomes have been reported (although there are ongoing trials). However, there are considerable epidemiological data with children and adolescents examining the association between sleep duration (typically nocturnal sleep) and weight status. Findings from both cross-sectional and prospective studies, although limited by their inability to demonstrate causation (i.e., that less sleep at night leads to increased weight status), are important for helping to shape our understanding of the potential role that sleep may play in the current obesity epidemic. Prospective studies, in particular, help to establish temporal relationships between sleep and pediatric obesity. The purpose of the present 
review is to provide a comprehensive update of current epidemiological studies that have assessed the association between sleep and obesity risk. Although obstructive sleep apnea is also associated with obesity risk, it is beyond the scope of the present paper. The reader is referred to Ievers-Landis \& Redline ${ }^{28}$ as well as the paper by (cite authors) in this Special Issue for a more comprehensive review. To build upon previous reviews, the present paper includes information on anthropometric indices (i.e., waist circumference, percent body fat) other than BMI, includes findings regarding sleep timing and quality (as opposed to only focusing on sleep duration), and reviews findings regarding possible mediators of the sleepweight relationship.

\section{Methods}

A systematic search for publications was performed using the PubMed database that included published studies through July 2010. Combinations of key words specific to sleep (e.g., sleep and sleeping), weight status (e.g., BMI, overweight, obesity, adiposity, weight fatness, food diet, and energy expenditure), and childhood and adolescence (e.g., child, children, adolescent, adolescence) were used. In addition, reference lists of relevant articles, and previously conducted relevant review papers/meta-analyses were reviewed to identify additional studies. Only studies that focused on children and adolescents (i.e., birth-18 years), and represented original empirical work (i.e., reviews and editorials were excluded) were included in the present review. Questions regarding inclusion of studies were decided by consensus. This resulted in the inclusion of 38 studies (with 2 additional duplicates) in the present review.

\section{Results}

\section{Sleep Duration and Obesity Risk}

Table 1 presents findings from studies that assessed the association between sleep duration and obesity risk in children and adolescents. ${ }^{29-58}$ It represents 30 studies from 16 countries. For ease of comparison, studies presented in the Table are those in which main findings are presented as odds ratios. Two groups published subsequent studies using the same data set, but controlling for additional confounding variables. These subsequent studies were consistent with initial findings and are referenced as footnotes to the Table. The majority of studies present cross-sectional findings $(\mathrm{N}=24)$ with 6 studies assessing the association between sleep duration and weight status prospectively. As can be seen in the table, the majority of studies assessed the construct of sleep duration exclusively through parent- or self-report $(\mathrm{N}=28)^{29-32,34-40,42-57}$ with two additional studies assessing sleep length via actigraphy. ${ }^{33,41}$ In contrast, the majority of studies $(\mathrm{N}=27)$ used measured height and weight to calculate body mass index in children with only two studies using parent- or selfreport $^{38,46,58}$, and one additional study in which it was unclear whether caretaker report or measured height and weight were obtained. ${ }^{56}$

As can be seen in the Table, for cross-sectional studies, the reference values for sleep length used to determine obesity risk varied from less than 7 hours of sleep/night to $\geq 12$ hours/ night. Despite these differences in how referents were defined, all studies demonstrated negative associations between sleep duration and obesity risk. It is important to note that most studies found significant results even after controlling for potential confounding variables (e.g., parental BMI, birth weight, television viewing; see Table for specific confounders controlled for in each study). However, it is also important to note that not every category of sleep was associated with increased risk of obesity. For example, Sekine et al._ENREF 14 found that in comparison to children who slept 11 hours or more each night, there was no increased risk for obesity for children sleeping less than 9 hours or 10-11 hours per night, but that there was an increased risk for obesity for children sleeping 9-10 
hours per night. ${ }^{30}$ Furthermore, when associations were examined separately in boys and girls, some studies found significant results for one gender but not the other. $37,47,49,50$

In addition to those studies presented in Table 1, six additional studies were conducted, but did not present findings in terms of odds ratios. ENREF 44, ENREF 47 ${ }^{59-64}$ All six studies found consistent results with less sleep being associated with an increased risk of obesity. However, one study only assessed this association in adolescent females, ${ }^{63}$ and a second study only found significant results in females. ${ }^{61}$

Six prospective studies were also identified (see Table ${ }^{52-57}$ ). Findings are consistent with cross-sectional studies. For example, Snell and colleagues found that for every additional hour of sleep obtained at time 1 (when children were 3-12 years of age), caretaker-reported BMI decreased by $0.75 \mathrm{~kg} / \mathrm{m}^{2}$ at time 2 (when children were 8-18 years old)_ENREF $37 .{ }^{53}$ Similarly, Touchette and colleagues found that between $2 \frac{1}{2}$ years and 6 years of age, children who consistently obtained "short sleep" were 2.9 times more likely to be overweight or obese than children who consistently slept 11 hours or more each night even after controlling for potential confounding factors _ENREF $40 .{ }^{56}$ Consistent with these findings, but over a much longer follow-up, Landhuis et al. found that for every additional hour of sleep obtained during childhood (averaged across 5-11 years), individuals had a 35\% reduced risk of obesity at age 32 years_ENREF 39.55

\section{Sleep Duration and Other Anthropometric Indices}

In addition to risk for overweight and obesity, more recent studies assessed the association between sleep duration and other indices of body composition. Eleven studies were identified; three of which used two or more measures to assess body fat ENREF $35 .{ }^{47,49,61}$ Five studies utilized skinfold thickness ${ }^{34,49,57,62,65}$, four used waist circumference ${ }^{37,47,49,61}$, and three used bioelectrical impedence analysis (BIA). ${ }^{32,41,66}$ Two additional studies used another measure such as dual x-ray absorptiometry (DEXA) ${ }^{61}$ and air displacement plethysmography. ${ }^{47}$ Regardless of measure, however, an increase in sleep duration was consistently found to be associated with lower body fat.

For example, Nixon and colleagues found that compared to 7-year-old children sleeping 9 hours or more/night (as measured by actigraphy), children sleeping less than 9 hours/night had an increase of $3.34 \%$ body fat (as measured by BIA)_ENREF $25 .{ }^{41}$ Similarly, von Kries et al. found that when compared with 5-6-year-old children sleeping less than 10 hours/night, children sleeping $11 \frac{1 / 2}{2}$ hours or more/night had a decreased risk for high body fat (defined as excessive fat mass $>90^{\text {th }}$ percentile for age and gender using BIA)_ENREF $16 .{ }^{32}$

It should be noted that three studies found that significant findings varied across gender. In a sample of 10-20-year-old twins, Yu et al. found that shortened sleep length ( $<8 \mathrm{hrs} / \mathrm{night}$ ) was negatively associated with total body fat and truncal fat, and positively associated with percent lean body mass as measured by DEXA in females only_ENREF $44 .{ }^{61}$ Similarly, although Hitze et al. found that short sleep was associated with increased fat free mass in both genders (using air displacement plethysmography), they only found differences in percent body fat in females_ENREF_ $31 .{ }^{47}$

Findings regarding waist circumference and nocturnal sleep length were less consistent than above with one study finding that greater sleep duration was associated with smaller waist circumferences, ${ }^{49}$ and the three remaining studies finding significant results varying depending upon gender. ${ }^{37,47,61}$ For example, although Hitze et al. found significant findings across genders in linear analyses, when comparing short versus long sleepers, only short sleeping females had significantly larger waist circumferences_ENREF $31 .{ }^{47} \mathrm{Yu}$ et al. also 
found a significant association between sleep duration and waist circumference in females only_ENREF $44 .{ }^{61}$ In contrast, Eisenmann et al. found that greater sleep duration was associated with decreased waist circumference in boys 7-16 years old, and only in 7-10year-old girls (but not their older counterparts) ${ }^{37}$ ENREF 21.

\section{Additional Sleep Indices and Obesity Risk}

In addition to the assessment of sleep duration, several studies assessed other sleep measures to determine whether additional sleep parameters may be associated with obesity risk. The primary variable of interest was the timing of sleep (i.e. bedtime and rise time) $)^{30,31,53,63,64}$, which was typically assessed with a single-item question (e.g. "over the past week, what was your typical bedtime?"). Together, these studies suggest that later bedtimes are associated with increased risk of obesity. ${ }^{31,53,63,64}$ ENREF 15 However, no association between rise time and obesity risk was found in these studies. ${ }^{31,53}$ Of note, one study with preschool-age children ( 3 years) found that early rise time (i.e., $\leq 7: 00 \mathrm{am}$ ) was associated with an increased obesity risk, but that later bedtime was not. ${ }^{30}$

In addition to bedtime and rise time, three additional studies assessed the association between irregular or problematic sleep and obesity risk. In the first study, parent report of "irregular sleep habits" at 2 to 4 years of age was independently associated with obesity risk in young adulthood (i.e., at 21 years) ${ }^{67}$ Furthermore, Wing and colleagues attempted to assess how "catching up" on sleep on weekends and holidays may influence children's risk for obesity. ${ }^{46}$ Findings suggested that compared to children who slept greater than 10 hours/ night, children who persistently slept 8 hours or less on weekdays and weekends or on weekdays and during holidays, were at the greatest risk for obesity ( $\mathrm{OR}$ adj $=2.59$ [1.22-5.48] and 2.32 [1.00-5.53], respectively). In contrast to findings from these studies, after adjusting for potential confounding variables, no association was found between parent reported sleep problems (using a modified version of the Children's Sleep Habits Questionnaire) in the $3^{\text {rd }}$ or $6^{\text {th }}$ grades and obesity risk in the $6^{\text {th }}$ grade. ${ }^{54}$

Finally, two studies assessed the association between stages of sleep and obesity risk. In the first study (which is also presented in part in the Table), Liu et al. found that reduced rapid eye movement (REM) time and reduced REM density were each associated with increased obesity risk in children 7-17 years old. ${ }^{43}$ In a second study of 52 adolescents $12-18$ years who presented to a sleep clinic, greater stage 1 sleep was found for adolescents who were obese compared to those who were normal weight, and greater slow wave sleep was also found in adolescents who were categorized as overweight compared to those who were obese. $^{68}$

\section{Potential Mediators of the Sleep-Weight Association}

Several studies have moved beyond documenting sleep-weight associations to examining variables (e.g. eating) that may mediate the relationship between sleep and obesity risk. For example, Landis et al. found that food cravings were higher in those with more daytime/less nocturnal sleep. ${ }^{69}$ Touchette et al found that parent report of child overeating (at 6 years old) may play a small role in the association between short sleep and BMI. ${ }^{56}$ When removed from the statistical model to predict BMI, there was a small increase in the odds for children classified as "short persistent" sleepers to be obese (see table 1). Finally, Westerlund et al. found that shorter sleep was associated with greater consumption of energy-dense foods such as pizza, pasta, and refined sugars. ${ }^{70}$ This relationship was stronger in boys and on weekdays. Additional gender differences included greater problems with waking in the morning being associated with increased intake of energy-dense foods in boys, and longer weekday sleep duration being associated with greater consumption of nutrient-dense foods (i.e., fruits and vegetables) in girls. 


\section{Discussion}

Our understanding of the role of sleep duration in the current pediatric obesity epidemic is rapidly unfolding. Pediatric studies identified and included in the present review suggest that children who sleep less are at increased risk for being and/or becoming overweight/obese. This significant relationship was found in both cross-sectional and prospective studies, and persisted in most studies even after controlling for potential confounders such as parental BMI, birth weight, and television viewing. Findings from the present review are consistent with conclusions drawn from other systematic reviews and meta-analyses ${ }^{71-76}$ including two meta-analyses that demonstrated that children with "shortened sleep" were at a 56-89\% increased risk for obesity. ${ }^{72,75}$ Findings also build upon previous reviews by demonstrating the potential influence of sleep length on other measures of adiposity such as waist circumference and percent body fat. The consistency in findings across anthropometric measures increases confidence in findings, and suggests that increased BMI associated with less sleep is likely due to increased deposits of adipose tissue. ${ }^{62}$

Also building upon previous work, studies included in the present review examined the association between additional sleep indices (other than sleep duration) and weight-related outcomes. Studies with school-age children and adolescents consistently found that later bedtimes were associated with increased obesity risk while rise times were unrelated. ${ }^{31,53,63,64}$ It is possible that later bedtimes are simply a proxy for shorter sleep duration, which would account for their significant association with obesity risk. However, it is also possible that circadian phase-delay may play a role in establishing risk of overweight/ obesity, particularly given research suggesting the importance of circadian clocks in metabolism and obesity. ${ }^{77}$

Beyond later bedtimes, it is unclear what other sleep indices may confer obesity risk and/or protection. While findings from Wing et al. regarding the protective benefit of "catching up" on sleep on weekends and holidays are interesting, it is unclear how these findings would translate into clinical practice recommendations given the importance of consistent sleepwake habits for the promotion of good sleep in children. ${ }^{46}$ Future studies are needed to further assess the role of "catching up" on sleep as well as the potential influence of other irregular/problematic sleep habits, including measures of sleep quality and sleep staging, on obesity risk.

An additional focus of more recent studies is attempting to better understand the potential pathways through which sleep affects BMI. These studies have focused on eating behaviors and suggest that they may be influenced by sleep duration. ${ }^{56,69,70}$ However, findings are largely limited by reliance on self-report measures, inconsistencies in findings both across and within studies, and lack of experimental manipulation of sleep duration. To strengthen confidence in the association between sleep and obesity risk via eating pathways, experimental and/or intervention research studies need to be conducted with children.

Furthermore, although change in food intake may represent one pathway through which sleep duration influences obesity risk, a number of additional pathways are possible. As shown in the Figure, a number of factors, including daytime sleepiness/fatigue and subsequent changes in activity level as well as metabolic changes may play an important role in the sleep-weight relationship. For example, cross-sectional research demonstrate that sleep is negatively impacted by engagement in sedentary activities such as television viewing, ${ }^{78-80}$ and positively associated with engagement in exercise (Chen et al., 2006).

However, it remains unclear whether shortened sleep results in subsequent changes in children's activity choices. Furthermore, experimental studies with adults have demonstrated physiological changes as a result of shortened sleep, which may promote weight gain. These 
include changes in growth hormone, prolactin, cortisol, thyrotropin, and insulin ${ }^{17}$ as well as leptin ${ }^{18,19}$ and ghrelin ${ }^{20}$ both of which are associated with increased hunger, appetite, motivation to eat, and food intake. ${ }^{21-23}$ Studies with children in this regard are sparse, and to our knowledge, no experimental studies with children have been published. However, extant correlational research with children demonstrate an association between sleep and metabolic abnormalities, including lower fasting C-peptide, ${ }^{81}$ hyperglycemia ${ }^{82}$ as well as higher fasting insulin, peak insulin, and insulin resistance (i.e., increased HOMA-IR levels and lower WBISI levels). ${ }^{83}$ Taken together, study findings suggest the need to further explore the multiple pathways through which sleep duration influences obesity risk.

Despite the consistency in findings, a number of limitations of studies should be noted. First, the reviewed studies were predominantly cross-sectional in nature. Thus, the potential causal influence of sleep duration on obesity risk cannot be established. Although six prospective studies were identified and aid in our understanding of the temporal relationship between sleep length and obesity risk, they cannot demonstrate that less sleep causes increases in weight status, and hence obesity. As noted above, future experimental research will need to be conducted prior to being able to determine causal links. Second, the measurement of sleep length in reviewed studies was primarily based on self- or parent-report, which calls into question reliability and validity of measures, particularly when single-item measures were used. Only three studies evaluated sleep length with more objective measures such as actigraphy and PSG (and were often limited by having only one day of measurement). Third, studies often used different reference values for sleep length in analyses, which makes comparisons across studies challenging. Finally, findings across studies were not always consistent across sleep categories or across gender. Inconsistencies across sleep categories may suggest that the effect of sleep on obesity risk may be small in size. However, findings regarding inconsistencies across gender are less clear since some studies found significant results in males rather than females and others found contrary results. Some of these gender differences may be due to an interaction of child gender with child age, ethnicity and/or race and pubertal status. Systematic assessment of how demographic factors may interact with sleep length in conferring obesity risk could help to explain these discrepant findings.

Taken together, study findings suggest that sleep length is associated with obesity risk. Findings also point towards changes in eating pathways that may lead to increased accumulation of adipose tissue as a potential mediator of this association. However, more research is needed to establish shortened sleep duration as a true risk factor that can be targeted in pediatric weight control interventions. Although it may not yet be prudent to prescribe changes in sleep to prevent obesity at a population level, there is ample, accumulated data, which strongly argues for systematically evaluating the potential role that enhancing sleep may have in combating the current obesity epidemic. Evidence also suggests a number of points of intervention for providers when working with children who are overweight and obese. These are highlighted below.

First, given the fact that multiple studies have shown that shortened sleep length is associated with increased BMI, assessment of sleep duration in children who are overweight and obese is important. ${ }^{71}$ Simple questions regarding obese children's sleep habits on weekdays and weekends could identify a number of children who could benefit from recommendations to obtain a good night's sleep. Given the well-documented deleterious effects of sleep on children's mood and daytime functioning, such a minimal intervention could promote a number of benefits across multiple domains. Furthermore, given the sensitive nature of addressing weight-related concerns with families, discussion of sleep may provide a nice point of entry to begin to discuss the importance of healthy lifestyles (including eating and activity behaviors) for promoting optimal health in childhood and 
beyond. In addition to assessment of sleep duration, providers should also consider concurrent treatment of sleep and weight problems..$^{71}$ At the heart of treatments for both shortened sleep duration and overweight/obesity are the use of effective behavioral strategies, and the importance of targeting key behaviors such as television viewing.

It is clear from recent reviews, including the present one, that we are only beginning to understand the role of sleep in our current obesity epidemic. Consistency in study findings suggest that it is now time to begin to assess for sleep disturbances in children who are overweight and obese, to consider targeting sleep and obesity as comorbid conditions, and to begin to explore through experimental studies how changes in sleep length may influence obesity risk. Sleep duration represents an intriguing and potentially effective tool for promoting healthier weight in children and adolescents. It is time to move beyond epidemiological studies to further our understanding regarding how effective an approach it will be.

\section{Acknowledgments}

This work was supported in part by Grant Nos. 1-09-JF-22 from the American Diabetes Association, U01 CA150387 from the National Institutes of Health, T32 HL076134 from the National Institutes of Health.

\section{References}

1. Ogden CL, Carroll MD, Curtin LR, et al. Prevalence of high body mass index in US children and adolescents, 2007-2008. Jama. 2010; 303:242. [PubMed: 20071470]

2. Daniels SR. The consequences of childhood overweight and obesity. Future Child. 2006; 16:47. [PubMed: 16532658]

3. Freedman DS, Dietz WH, Srinivasan SR, et al. The relation of overweight to cardiovascular risk factors among children and adolescents: the Bogalusa Heart Study. Pediatrics. 1999; 103:1175. [PubMed: 10353925]

4. Ludwig DS, Peterson KE, Gortmaker SL. Relation between consumption of sugar-sweetened drinks and childhood obesity: a prospective, observational analysis. Lancet. 2001; 357:505. [PubMed: 11229668]

5. Wardle J, Cooke L. The impact of obesity on psychological well-being. Best Pract Res Clin Endocrinol Metab. 2005; 19:421. [PubMed: 16150384]

6. Jelalian, E.; Hart, CN. Pediatric Obesity. In: Roberts, MC.; Steele, RG., editors. Handbook of Pediatric Psychology. Fourth. New York: Guilford Press; 2009.

7. Services USDoHaH: Developing Healthy People 2020, in Nutrition and Weight Status. 2010

8. Summerbell CD, Waters E, Edmunds LD, et al. Interventions for preventing obesity in children. Cochrane Database Syst Rev:CD001871. 2005

9. Brown T, Summerbell C. Systematic review of school-based interventions that focus on changing dietary intake and physical activity levels to prevent childhood obesity: an update to the obesity guidance produced by the National Institute for Health and Clinical Excellence. Obes Rev. 2009; 10:110. [PubMed: 18673306]

10. Oude Luttikhuis H, Baur L, Jansen H, et al. Interventions for treating obesity in children. Cochrane Database Syst Rev:CD001872. 2009

11. Pratt JS, Lenders CM, Dionne EA, et al. Best practice updates for pediatric/adolescent weight loss surgery. Obesity (Silver Spring). 2009; 17:901. [PubMed: 19396070]

12. Iglowstein I, Jenni OG, Molinari L, et al. Sleep duration from infancy to adolescence: reference values and generational trends. Pediatrics. 2003; 111:302. [PubMed: 12563055]

13. Dollman J, Ridley K, Olds T, et al. Trends in the duration of school-day sleep among 10- to 15year-old South Australians between 1985 and 2004. Acta Paediatr. 2007; 96:1011. [PubMed: 17524028]

14. NSF. Sleep in America Poll. 2004 
15. Mindell, J.; Owens, JA., editors. A clinical guide to pediatric sleep. Philadelphia: Lipincott Williams \& Wilkins; 2003.

16. Ferber R. Childhood Sleep Disorders. Neurologic Clinics. 1996; 14:493. [PubMed: 8871974]

17. Copinschi G. Metabolic and endocrine effects of sleep deprivation. Essent Psychopharmacol. 2005; 6:341. [PubMed: 16459757]

18. Christian G, Nelson BP, Sandra M, et al. Preliminary observations on the effects of sleep time in a sleep restriction paradigm. Sleep Medicine. 2003; 4:177. [PubMed: 14592319]

19. Spiegel K, Leproult R, L'Hermite-Baleriaux M, et al. Leptin levels are dependent on sleep duration: relationships with sympathovagal balance, carbohydrate regulation, cortisol, and thyrotropin. J Clin Endocrinol Metab. 2004; 89:5762. [PubMed: 15531540]

20. Taheri S, Lin L, Austin D, et al. Short sleep duration is associated with reduced leptin, elevated ghrelin, and increased body mass index. PLoS Med. 2004; 1:210.

21. Wren AM, Seal LJ, Cohen MA, et al. Ghrelin enhances appetite and increases food intake in humans. Journal of Clinical and Endocrinology Metabolism. 2001; 86:5992.

22. Levin F, Edholm T, Schmidt PT, et al. Ghrelin stimulates gastric emptying and hunger in normalweight humans. J Clin Endocrinol Metab. 2006; 91:3296. [PubMed: 16772353]

23. Mars M, de Graaf C, de Groot CP, et al. Fasting leptin and appetite responses induced by a 4-day 65\%-energy-restricted diet. Int J Obes (Lond). 2006; 30:122. [PubMed: 16158086]

24. Nedeltcheva AV, Kilkus JM, Imperial J, et al. Sleep curtailment is accompanied by increased intake of calories from snacks. Am J Clin Nutr. 2009; 89:126. [PubMed: 19056602]

25. Brondel L, Romer MA, Nougues PM, et al. Acute partial sleep deprivation increases food intake in healthy men. Am J Clin Nutr. 2010; 91:1550. [PubMed: 20357041]

26. Dru M, Bruge P, Benoit O, et al. Overnight duty impairs behaviour, awake activity and sleep in medical doctors. Eur J Emerg Med. 2007; 14:199. [PubMed: 17620909]

27. Schmid SM, Hallschmid M, Jauch-Chara K, et al. Short-term sleep loss decreases physical activity under free-living conditions but does not increase food intake under time-deprived laboratory conditions in healthy men. Am J Clin Nutr. 2009; 90:1476. [PubMed: 19846546]

28. Ievers-Landis CE, Redline S. Pediatric sleep apnea: implications of the epidemic of childhood overweight. Am J Respir Crit Care Med. 2007; 175:436. [PubMed: 17158283]

29. Locard E, Mamelle N, Billette A, et al. Risk factors of obesity in a five year old population. Parental versus environmental factors. Int J Obes Relat Metab Disord. 1992; 16:721. [PubMed: 1330951]

30. Sekine M, Yamagami T, Hamanishi S, et al. Parental obesity, lifestyle factors and obesity in preschool children: results of the Toyama Birth Cohort study. J Epidemiol. 2002; 12:33. [PubMed: 11848182]

31. Sekine M, Yamagami T, Handa K, et al. A dose-response relationship between short sleeping hours and childhood obesity: results of the Toyama Birth Cohort Study. Child Care Health and Development. 2002; 28:163.

32. von Kries R, Toschke AM, Wurmser H, et al. Reduced risk for overweight and obesity in 5- and 6y-old children by duration of sleep--a cross-sectional study. International Journal of Obesity. 2002; 26:710. [PubMed: 12032757]

33. Gupta NK, Mueller WH, Chan W, et al. Is obesity associated with poor sleep quality in adolescents? Am J Hum Biol. 2002; 14:762. [PubMed: 12400037]

34. Padez C, Mourao I, Moreira P, et al. Prevalence and risk factors for overweight and obesity in Portuguese children. Acta Paediatr. 2005; 94:1550. [PubMed: 16303693]

35. Chen MY, Wang EK, Jeng YJ. Adequate sleep among adolescents is positively associated with health status and health-related behaviors. BMC Public Health. 2006; 6:59. [PubMed: 16524482]

36. Chaput JP, Brunet M, Tremblay A. Relationship between short sleeping hours and childhood overweight/obesity: results from the 'Quebec en Forme' Project. International Journal of Obesity (London). 2006; 30:1080.

37. Eisenmann JC, Ekkekakis P, Holmes M. Sleep duration and overweight among Australian children and adolescents. Acta Paediatr. 2006; 95:956. [PubMed: 16882569] 
38. Seicean A, Redline S, Seicean S, et al. Association between short sleeping hours and overweight in adolescents: results from a US Suburban High School survey. Sleep Breath. 2007; 11:285. [PubMed: 17440761]

39. Kuriyan R, Bhat S, Thomas T, et al. Television viewing and sleep are associated with overweight among urban and semi-urban South Indian children. Nutr J. 2007; 6:25. [PubMed: 17880729]

40. Knutson KL, Lauderdale DS. Sleep duration and overweight in adolescents: self-reported sleep hours versus time diaries. Pediatrics. 2007; 119:e1056. [PubMed: 17473079]

41. Nixon GM, Thompson JM, Han DY, et al. Short sleep duration in middle childhood: risk factors and consequences. Sleep. 2008; 31:71. [PubMed: 18220080]

42. Ievers-Landis CE, Storfer-Isser A, Rosen C, et al. Relationship of sleep parameters, child psychological functioning, and parenting stress to obesity status among preadolescent children. J Dev Behav Pediatr. 2008; 29:243. [PubMed: 18552704]

43. Liu X, Forbes EE, Ryan ND, et al. Rapid eye movement sleep in relation to overweight in children and adolescents. Arch Gen Psychiatry. 2008; 65:924. [PubMed: 18678797]

44. Wells JC, Hallal PC, Reichert FF, et al. Sleep patterns and television viewing in relation to obesity and blood pressure: evidence from an adolescent Brazilian birth cohort. Int J Obes (Lond). 2008; 32:1042. [PubMed: 18347603]

45. Bawazeer NM, Al-Daghri NM, Valsamakis G, et al. Sleep duration and quality associated with obesity among Arab children. Obesity (Silver Spring). 2009; 17:2251. [PubMed: 19498352]

46. Wing YK, Li SX, Li AM, et al. The effect of weekend and holiday sleep compensation on childhood overweight and obesity. Pediatrics. 2009; 124:e994. [PubMed: 19858153]

47. Hitze B, Bosy-Westphal A, Bielfeldt F, et al. Determinants and impact of sleep duration in children and adolescents: data of the Kiel Obesity Prevention Study. Eur J Clin Nutr. 2009; 63:739. [PubMed: 18665183]

48. Jiang F, Zhu S, Yan C, et al. Sleep and obesity in preschool children. J Pediatr. 2009; 154:814. [PubMed: 19243786]

49. Ozturk A, Mazicioglu M, Poyrazoglu S, et al. The relationship between sleep duration and obesity in Turkish children and adolescents. Acta Paediatr. 2009; 98:699. [PubMed: 19183420]

50. Sun Y, Sekine M, Kagamimori S. Lifestyle and overweight among Japanese adolescents: the Toyama Birth Cohort Study. J Epidemiol. 2009; 19:303. [PubMed: 19776497]

51. Anderson SE, Whitaker RC. Household routines and obesity in US preschool-aged children. Pediatrics. 2010; 125:420. [PubMed: 20142280]

52. Reilly JJ, Armstrong J, Dorosty AR, et al. Early life risk factors for obesity in childhood: cohort study. British Medical Journal. 2005; 330:1357. [PubMed: 15908441]

53. Snell EK, Adam EK, Duncan GJ. Sleep and the body mass index and overweight status of children and adolescents. Child Development. 2007; 78:309. [PubMed: 17328707]

54. Lumeng JC, Somashekar D, Appugliese D, et al. Shorter sleep duration is associated with increased risk for being overweight at ages 9 to 12 years. Pediatrics. 2007; 120:1020. [PubMed: 17974739]

55. Landhuis CE, Poulton R, Welch D, et al. Childhood Sleep Time and Long-Term Risk for Obesity: A 32-Year Prospective Birth Cohort Study. Pediatrics. 2008; 122:955. [PubMed: 18977973]

56. Touchette E, Petit D, Tremblay RE, et al. Associations between sleep duration patterns and overweight/obesity at age 6. Sleep. 2008; 31:1507. [PubMed: 19014070]

57. Taveras EM, Rifas-Shiman SL, Oken E, et al. Short sleep duration in infancy and risk of childhood overweight. Arch Pediatr Adolesc Med. 2008; 162:305. [PubMed: 18391138]

58. Hui LL, Nelson EA, Yu LM, et al. Risk factors for childhood overweight in 6- to 7-y-old Hong Kong children. Int J Obes Relat Metab Disord. 2003; 27:1411. [PubMed: 14574354]

59. Kagamimori S, Yamagami T, Sokejima S, et al. The relationship between lifestyle, social characteristics and obesity in 3-year-old Japanese children. Child Care Health Dev. 1999; 25:235. [PubMed: 10349521]

60. Agras WS, Hammer LD, McNicholas F, et al. Risk factors for childhood overweight: a prospective study from birth to 9.5 years. J Pediatr. 2004; 145:20. [PubMed: 15238901] 
61. Yu Y, Lu BS, Wang B, et al. Short sleep duration and adiposity in Chinese adolescents. Sleep. 2007; 30:1688. [PubMed: 18246978]

62. Bayer O, Rosario AS, Wabitsch M, et al. Sleep duration and obesity in children: is the association dependent on age and choice of the outcome parameter? Sleep. 2009; 32:1183. [PubMed: 19750923]

63. Maddah M, Rashidi A, Mohammadpour B, et al. In-school snacking, breakfast consumption, and sleeping patterns of normal and overweight Iranian high school girls: a study in urban and rural areas in Guilan, Iran. J Nutr Educ Behav. 2009; 41:27. [PubMed: 19161917]

64. Olds T, Blunden S, Dollman J, et al. Day type and the relationship between weight status and sleep duration in children and adolescents. Australian and New Zealand Journal of Public Health. 2010; 34:165.

65. Giugliano R, Carneiro EC. Factors associated with obesity in school children. J Pediatr (Rio J). 2004; 80:17. [PubMed: 14978544]

66. Duncan JS, Schofield G, Duncan EK, et al. Risk factors for excess body fatness in New Zealand children. Asia Pac J Clin Nutr. 2008; 17:138. [PubMed: 18364339]

67. Al Mamun A, Lawlor DA, Cramb S, et al. Do childhood sleeping problems predict obesity in young adulthood? Evidence from a prospective birth cohort study. Am J Epidemiol. 2007; 166:1368. [PubMed: 17855389]

68. Landis AM, Parker KP. A Retrospective Examination of the Relationship between Body Mass Index and Polysomnographic Measures of Sleep in Adolescents. The Journal of adolescent health : official publication of the Society for Adolescent Medicine. 2007; 40:89. [PubMed: 17185213]

69. Landis AM, Parker KP, Dunbar SB. Sleep, hunger, satiety, food cravings, and caloric intake in adolescents. J Nurs Scholarsh. 2009; 41:115. [PubMed: 19538695]

70. Westerlund L, Ray C, Roos E. Associations between sleeping habits and food consumption patterns among 10-11-year-old children in Finland. Br J Nutr. 2009; 102:1531. [PubMed: 19664303]

71. Hart CN, Jelalian E. Shortened sleep duration is associated with pediatric overweight. Behav Sleep Med. 2008; 6:251. [PubMed: 18853308]

72. Cappuccio FP, Taggart FM, Kandala NB, et al. Meta-analysis of short sleep duration and obesity in children and adults. Sleep. 2008; 31:619. [PubMed: 18517032]

73. Marshall NS, Glozier N, Grunstein RR. Is sleep duration related to obesity? A critical review of the epidemiological evidence. Sleep Med Rev. 2008; 12:289. [PubMed: 18485764]

74. Taheri S. The link between short sleep duration and obesity: we should recommend more sleep to prevent obesity. Archives of Disease in Childhood. 2006; 91:881. [PubMed: 17056861]

75. Chen X, Beydoun MA, Wang Y. Is sleep duration associated with childhood obesity? A systematic review and meta-analysis. Obesity (Silver Spring). 2008; 16:265. [PubMed: 18239632]

76. Patel SR, Hu FB. Short sleep duration and weight gain: a systematic review. Obesity (Silver Spring). 2008; 16:643. [PubMed: 18239586]

77. Bray MS, Young ME. Circadian rhythms in the development of obesity: potential role for the circadian clock within the adipocyte. Obesity Reviews. 2007; 8:169. [PubMed: 17300281]

78. Adam EK, Snell EK, Pendry P. Sleep timing and quantity in ecological and family context: a nationally representative time-diary study. J Fam Psychol. 2007; 21:4. [PubMed: 17371105]

79. Owens J, Maxim R, McGuinn M, et al. Television-viewing habits and sleep disturbance in school children. Pediatrics. 1999; 104:e27. [PubMed: 10469810]

80. Thompson DA, Christakis DA. The association between television viewing and irregular sleep schedules among children less than 3 years of age. Pediatrics. 2005; 116:851. [PubMed: 16199693]

81. Verhulst SL, Schrauwen N, Haentjens D, et al. Sleep duration and metabolic dysregulation in overweight children and adolescents. Arch Dis Child. 2008; 93:89. [PubMed: 18156481]

82. Tian Z, Ye T, Zhang X, et al. Sleep duration and hyperglycemia among obese and nonobese children aged 3 to 6 years. Arch Pediatr Adolesc Med. 2010; 164:46. [PubMed: 20048241]

83. Flint J, Kothare SV, Zihlif M, et al. Association between inadequate sleep and insulin resistance in obese children. J Pediatr. 2007; 150:364. [PubMed: 17382111] 


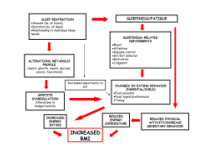

Figure 1.

Hypothesized Pathways through which Sleep Duration may Increase Obesity Risk*. *Courtesy of Judith Owens, M.D. 


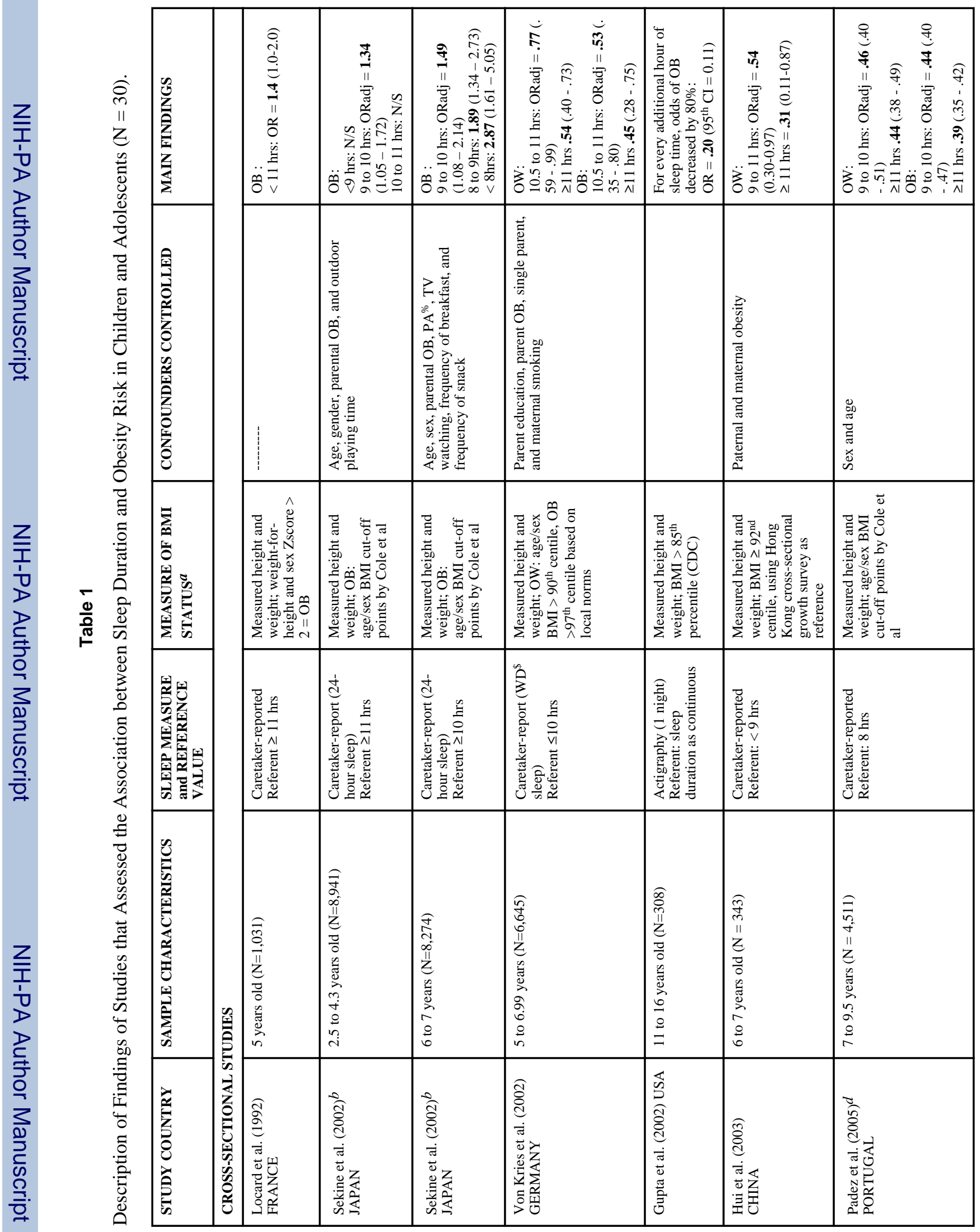

Pediatr Clin North Am. Author manuscript; available in PMC 2012 June 1. 


\begin{tabular}{|c|c|c|c|c|c|c|c|c|}
\hline 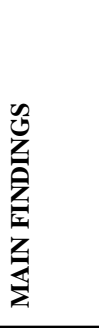 & 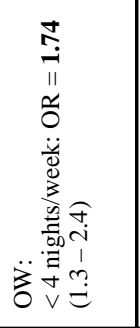 & 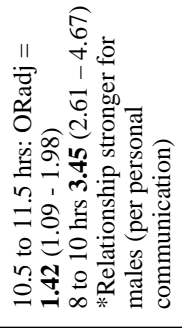 & 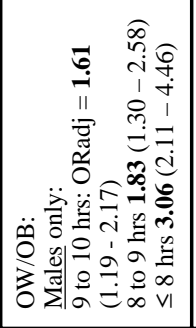 & 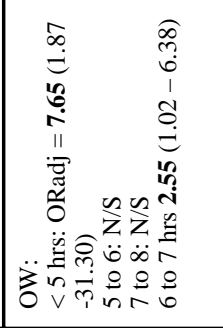 & 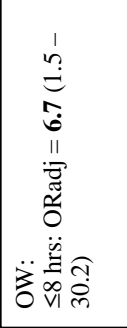 & 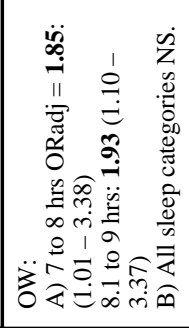 & 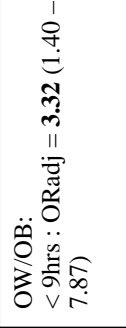 & 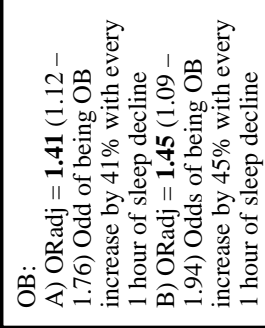 \\
\hline 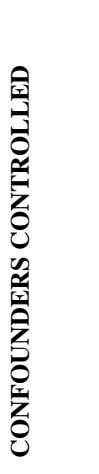 & & 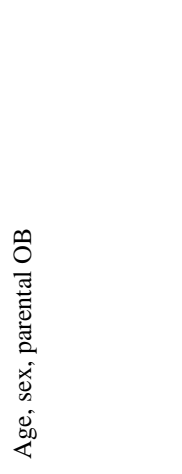 & 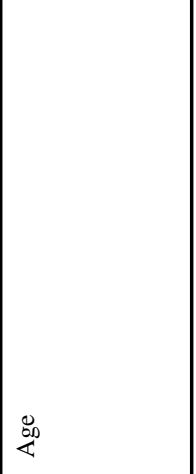 & 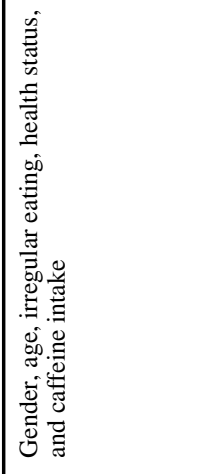 & 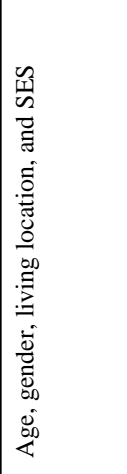 & 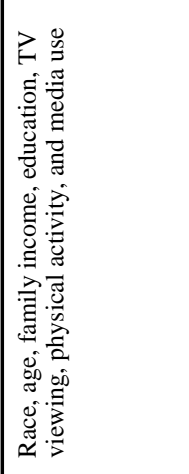 & 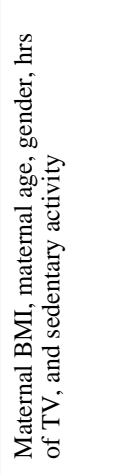 & 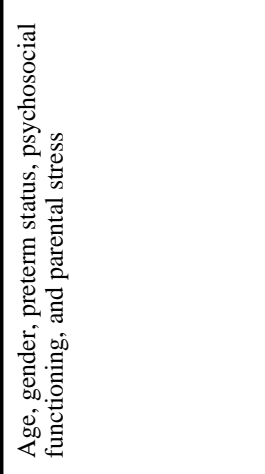 \\
\hline 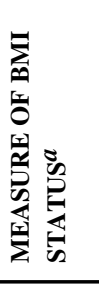 & 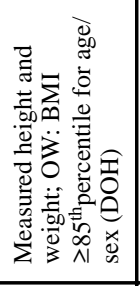 & 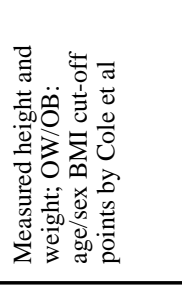 & 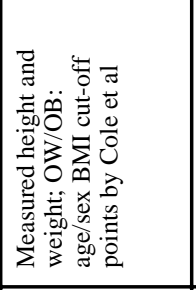 & 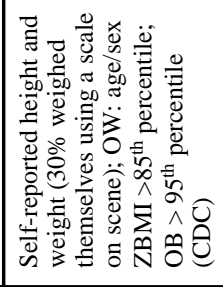 & 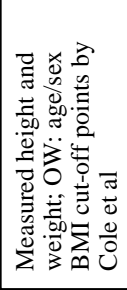 & 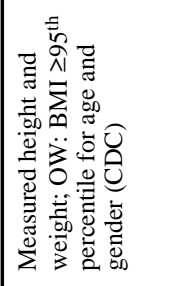 & 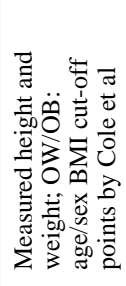 & 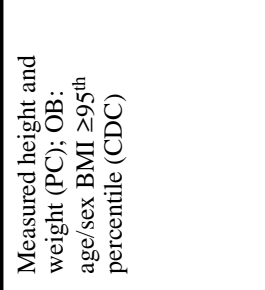 \\
\hline 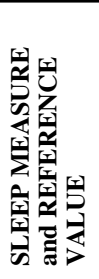 & 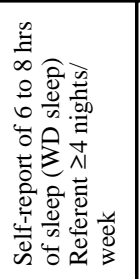 & 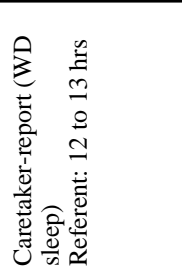 & 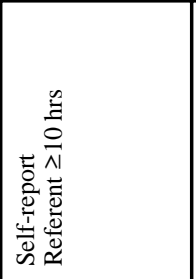 & 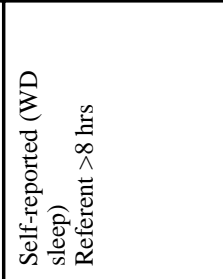 & 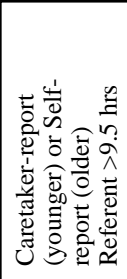 & 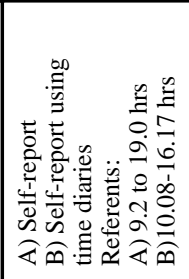 & 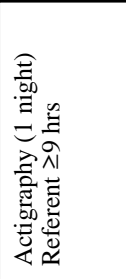 & 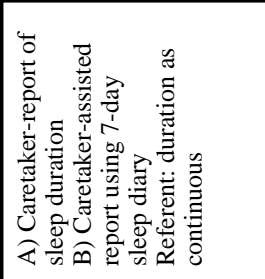 \\
\hline 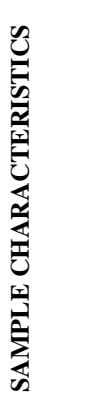 & 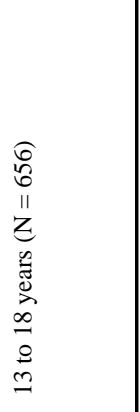 & 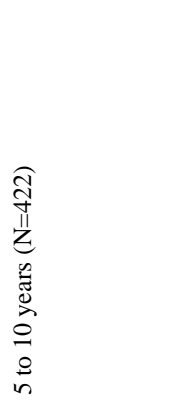 & 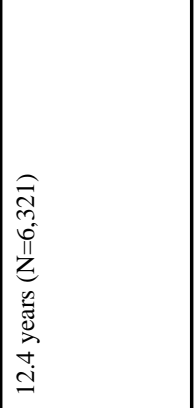 & 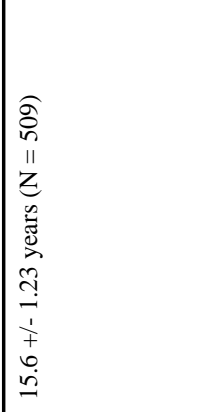 & 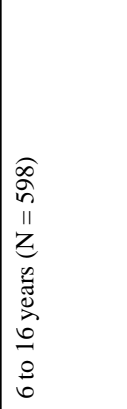 & 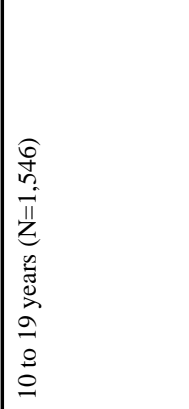 & 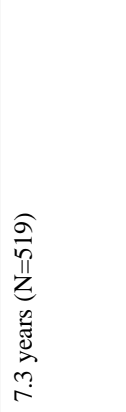 & 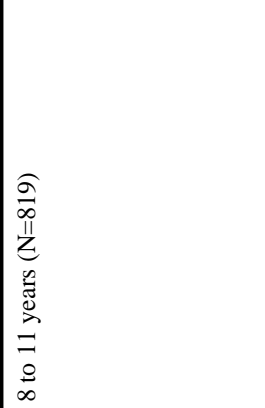 \\
\hline 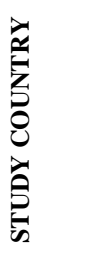 & 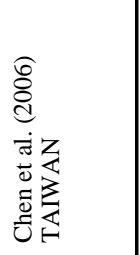 & 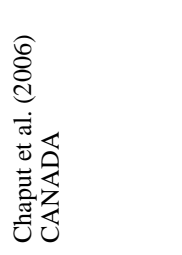 & 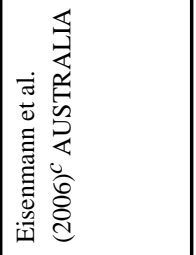 & 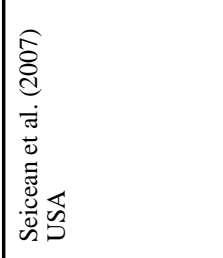 & 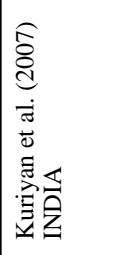 & 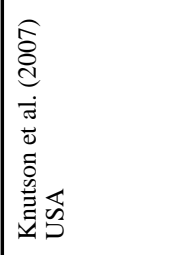 & 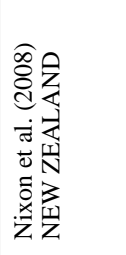 & 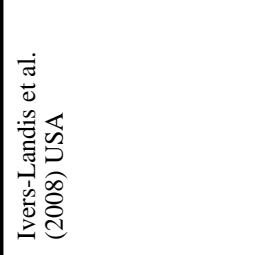 \\
\hline
\end{tabular}




\begin{tabular}{|c|c|c|c|c|c|c|c|}
\hline 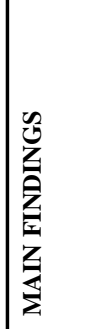 & 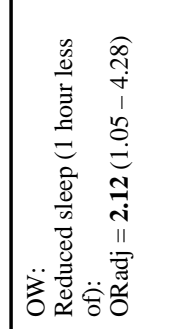 & 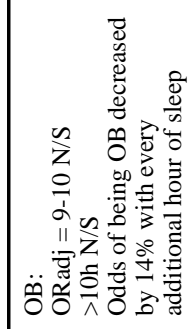 & 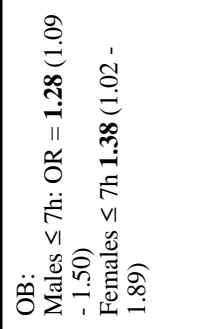 & 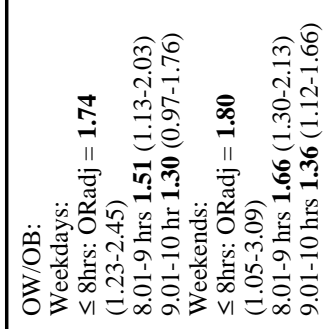 & 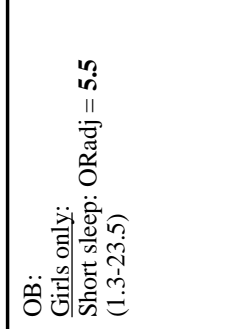 & 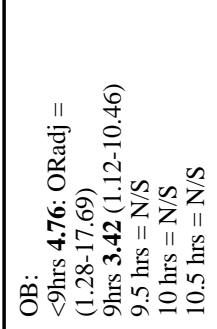 & 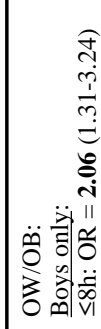 \\
\hline 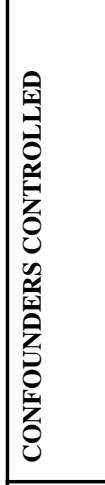 & 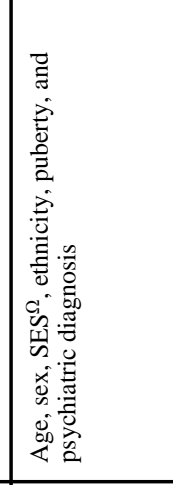 & 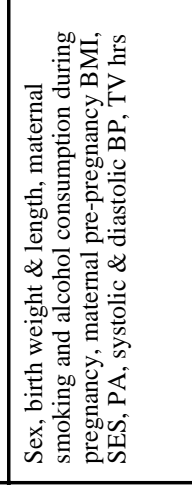 & & 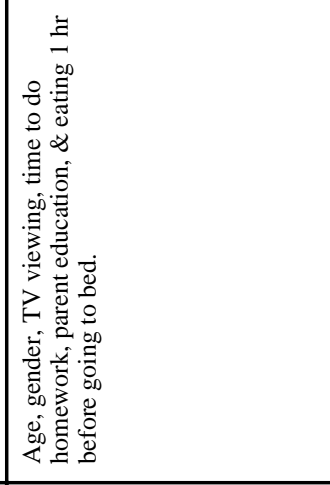 & 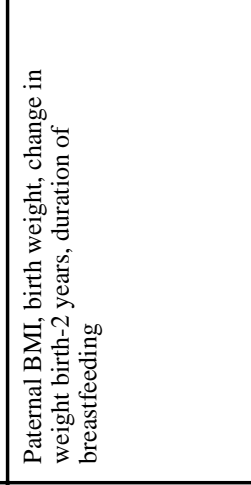 & 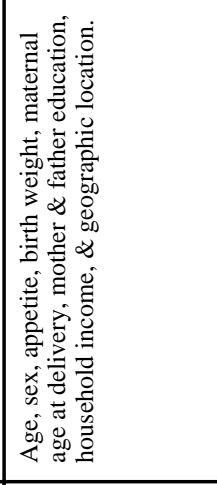 & \\
\hline 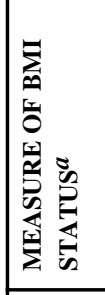 & 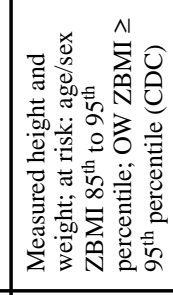 & 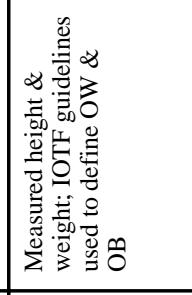 & 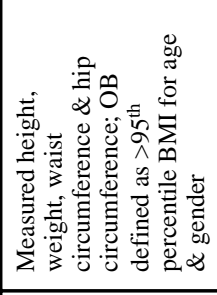 & 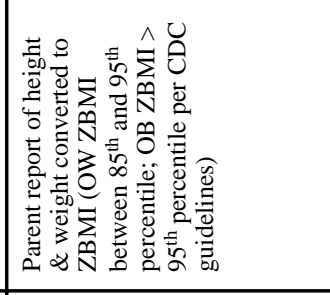 & 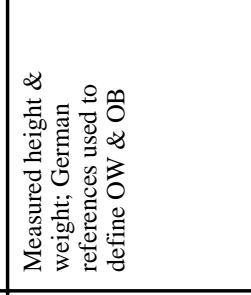 & 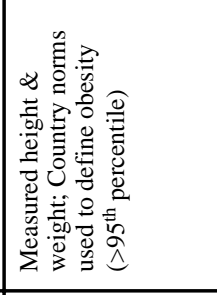 & 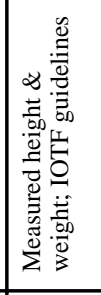 \\
\hline 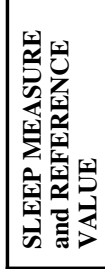 & 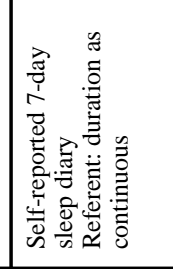 & 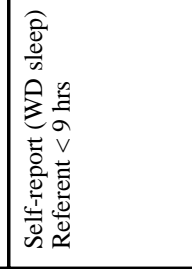 & 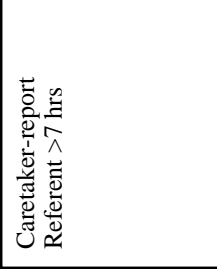 & 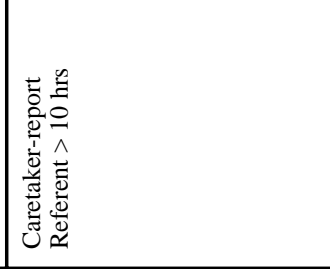 & 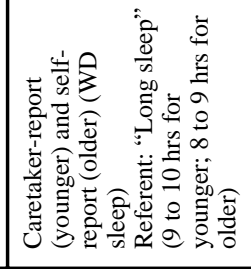 & 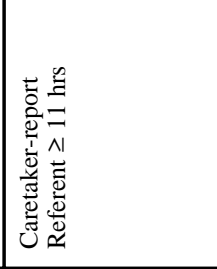 & 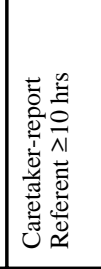 \\
\hline 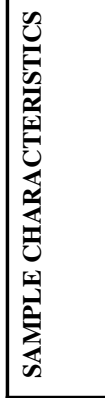 & 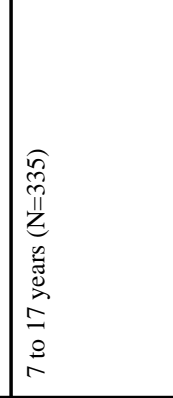 & 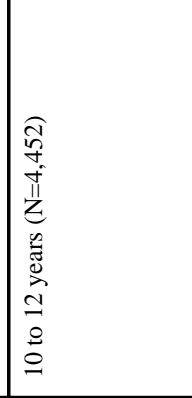 & 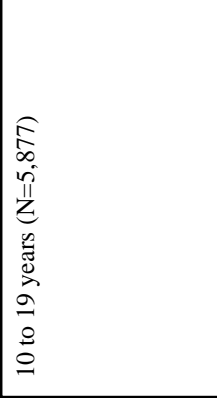 & 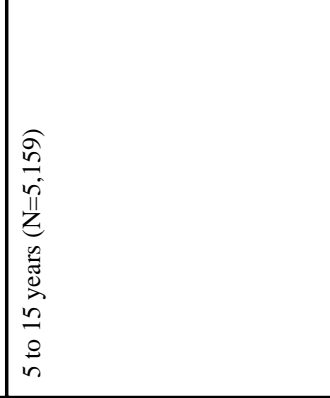 & 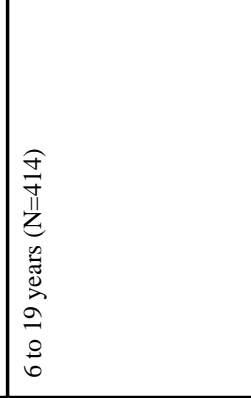 & 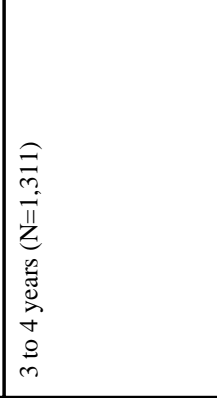 & 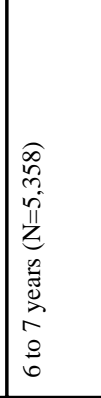 \\
\hline 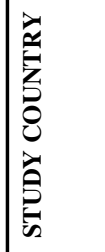 & 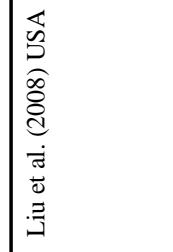 & 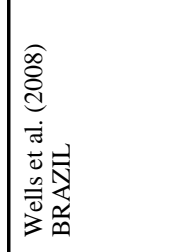 & 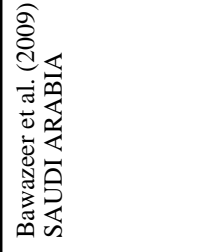 & 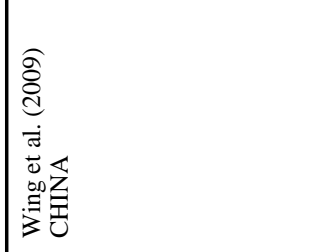 & 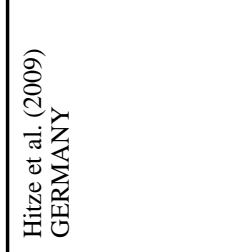 & 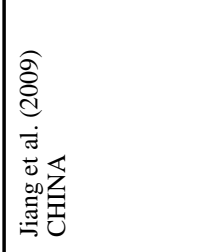 & 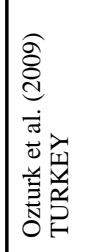 \\
\hline
\end{tabular}




\begin{tabular}{|c|c|c|c|c|c|c|c|c|c|}
\hline 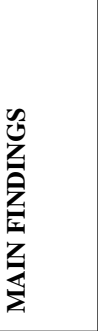 & 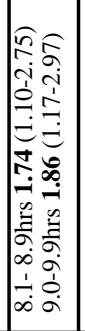 & 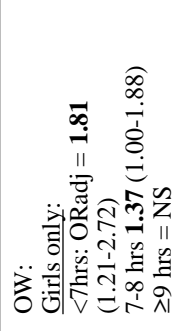 & 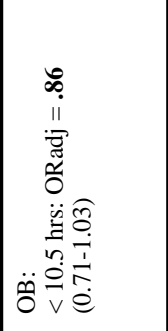 & & 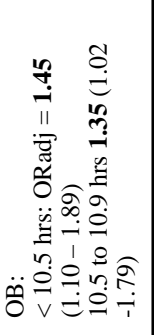 & 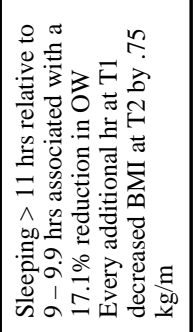 & 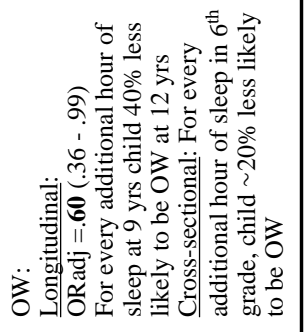 & 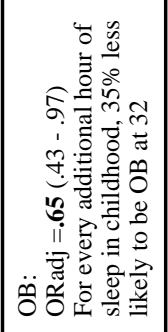 & 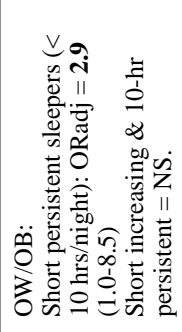 \\
\hline 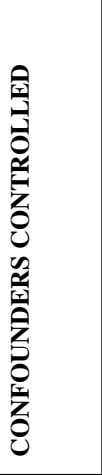 & & 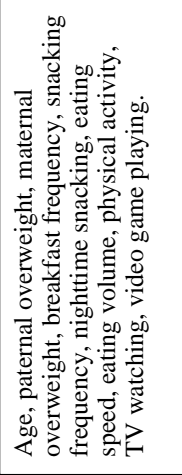 & 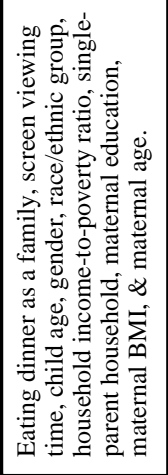 & & 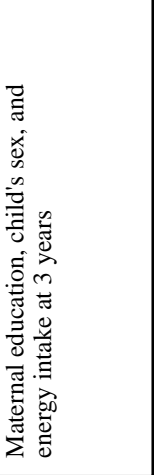 & 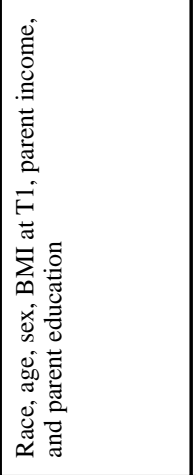 & 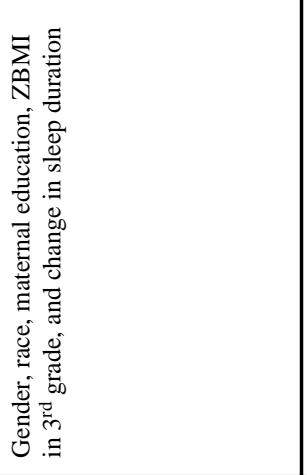 & 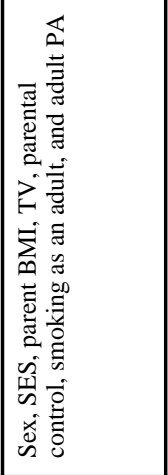 & 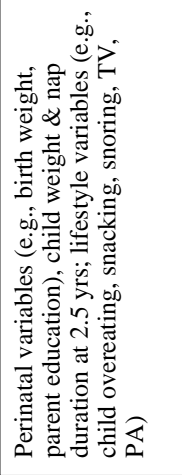 \\
\hline 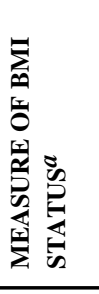 & 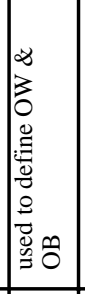 & 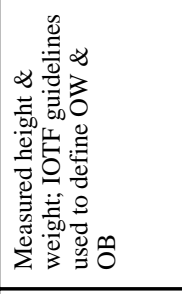 & 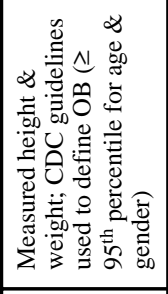 & & 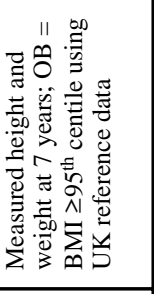 & 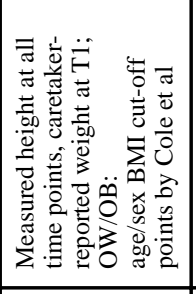 & 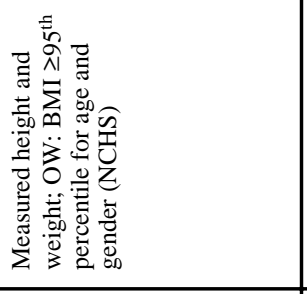 & 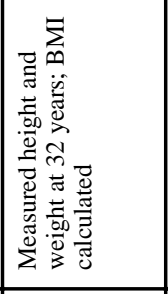 & 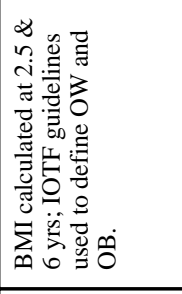 \\
\hline 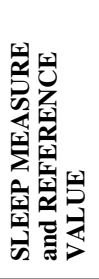 & & 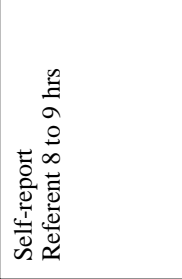 & 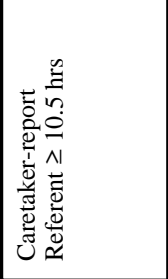 & & 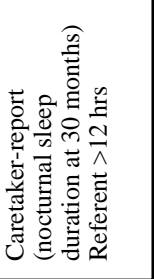 & 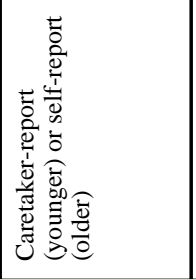 & 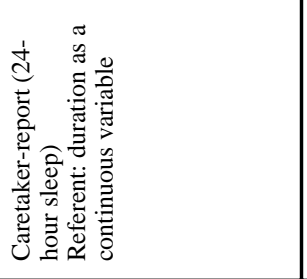 & 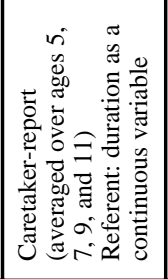 & 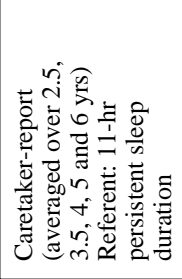 \\
\hline 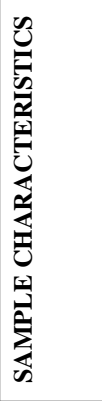 & & 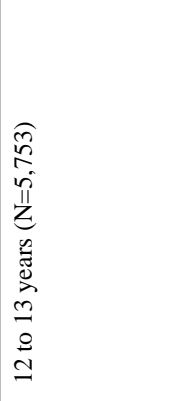 & 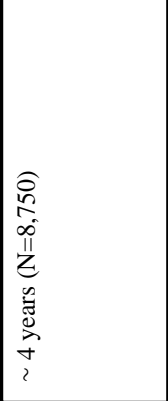 & ص & 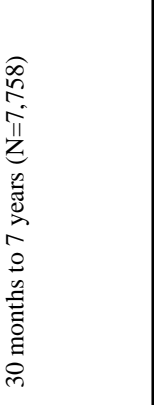 & 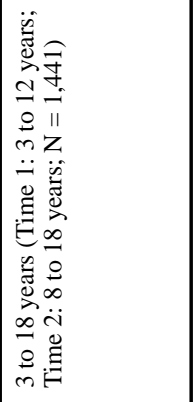 & 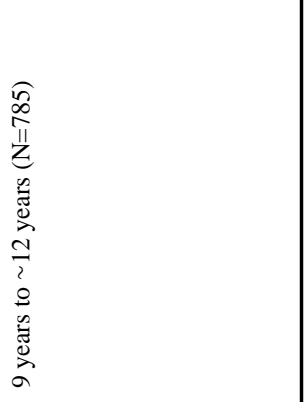 & 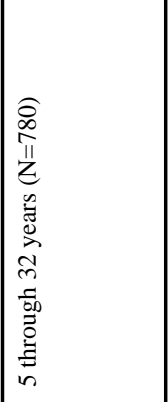 & 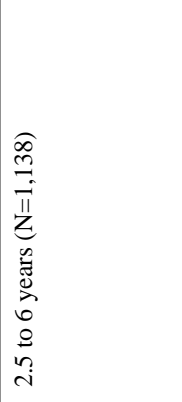 \\
\hline 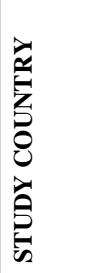 & & 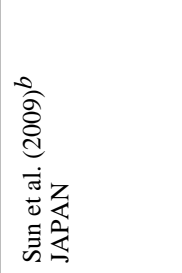 & 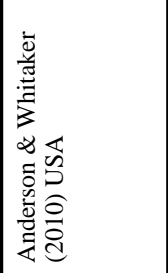 & 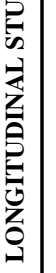 & 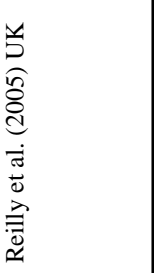 & 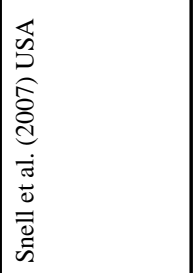 & 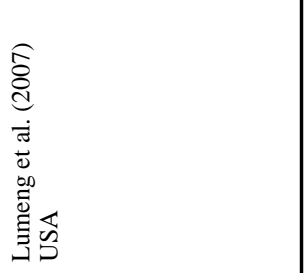 & 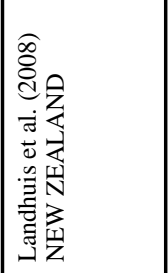 & 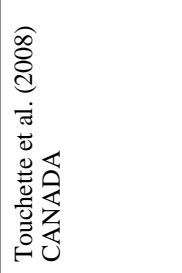 \\
\hline
\end{tabular}




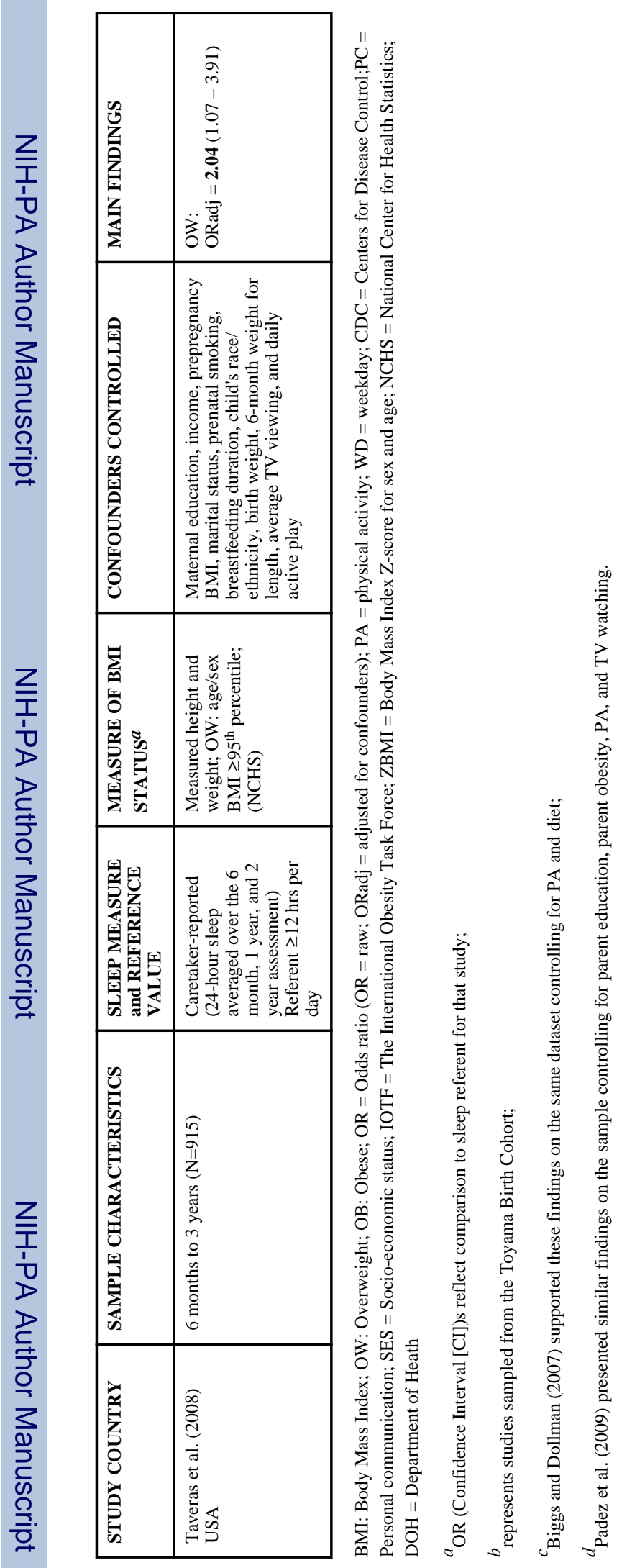

Pediatr Clin North Am. Author manuscript; available in PMC 2012 June 1. 